\title{
Unstructured Collaboration Versus Individual Practice for Complex Problem Solving: A Cautionary Tale
}

\author{
GEORGETTE YETTER \\ Oklahoma State University \\ TERRY B. GUTKIN \\ San Francisco State University \\ ANITA SAUNDERS \\ ANN M. GALLOWAY \\ Password Community Mentoring, Indianapolis \\ ROBIN R. SOBANSKY \\ University of Nebraska-Kearney \\ SAMUEL Y. SONG \\ University of North Carolina-Chapel Hill
}

\begin{abstract}
The authors used an experimental design to compare the effectiveness of unstructured collaborative practice with individual practice on achievement on a complex well-structured problem-solving task. Participants included postsecondary students $(N=257)$ from a liberal arts college serving primarily nontraditional students and from 2 state universities. Three videotaped instructional procedures were used: lessons on (a) introductory set theory, (b) a problem-solving heuristic, and (c) problem-solving modeling. Participants also engaged in active practice. A posttest assessed participant skills. A 2 (individual vs. collaborative treatment condition) $\times 2$ (nontraditional vs. traditional educational setting) analysis of variance revealed significant main effects for treatment condition. Students who practiced individually outperformed those who practiced collaboratively. Limitations and implications for future research are discussed.
\end{abstract}

Key words: collaborative practice, college students, complex problem solving, individual practice

Address correspondence to: Georgette Yetter, School Psychology, Oklahoma State University, 442 Willard Hall, Stillwater, OK 74078.E-mail: georgette.yetter@okstate.edu 
OVER THE PAST 20 YEARS, increasing numbers of students with special educational needs have enrolled in postsecondary institutions (Brinckerhoff, 1996). Despite adequate intelligence and motivation, these students are at greater risk for academic failure than their peers because of a combination of their learning difficulties and the demand characteristics of the postsecondary environment. As a result, it is more important than ever to find effective teaching techniques that can be implemented easily in the college classroom.

One family of teaching strategies involves peer collaboration in the classroom. Approaches to peer collaboration vary in terms of group size and the procedures selected for structuring peer interactions. Similarly, these approaches have been described under different labels, including peer tutoring, cooperative learning, and collaborative learning. The commonality among these approaches is that the process of peer collaboration requires students to be actively engaged with learning materials.

The utility of peer-supported learning is explained by several learning theories. According to the cognitive elaboration view, explaining material to a peer is especially important for helping students remember new information and for relating it to their existing knowledge. Cognitive elaboration is facilitated through activities such as thinking aloud; correcting partners' errors and omissions; providing detailed, elaborate explanations; and representing information in alternative forms, such as diagrams or drawings (Dansereau, 1988; Slavin, 1992; Webb, 1985, 1992). On the other hand, constructivist theory holds that peer interaction among individuals of similar developmental levels is critical for facilitating concept acquisition and complex reasoning (Vygotsky, 1978). Consequently, activities such as soliciting peers' opinions, identifying differences in opinion, and interrelating divergent viewpoints are fundamental to the learning process.

A third theory explains the advantage of peer collaboration on academic achievement as a function of the quality of social interactions among partners. According to the social interaction perspective, effective collaboration requires that partners work together under conditions of positive interdependence. Two prominent forms of positive interdependence are goal interdependence, in which each partner's contributions are necessary for the group to reach its goal, and reward interdependence, in which specific group contingencies are established to reward groups for achieving (Johnson \& Johnson, 1990; Slavin, 1996). Although there is evidence that both goal interdependence and reward interdependence promote higher achievement compared with individual practice, collaborative learning tasks that incorporate both goal and reward interdependence appear more promising (Lew, Mesch, Johnson, \& Johnson, 1986; Yueh \& Alessi, 1988).

Collaborative learning generally has been demonstrated to be an effective instructional approach across subject areas, ability levels, ethnic backgrounds, and grade level with students enrolled in primary and secondary education (Barron, 
2003; Calhoon \& Fuchs, 2003; Fuchs, Fuchs, \& Burish, 2000; Fuchs, Fuchs, \& Karns, 2001; Gardner et al., 2001; Mastropieri, Scruggs, Spencer, \& Fontana, 2003; McDonnell, Mathot-Buckner, Thorson, \& Fister, 2001). It also has been endorsed as a best-practice approach to educating students with special educational needs in primary and secondary education settings (Bender, 2002). These findings suggest that collaborative instructional methods have the potential to be beneficial for students with special learning needs in postsecondary settings. Because they require minimal instructor intervention, they also can be implemented easily in the college classroom.

Whereas studies investigating collaborative learning with postsecondary students have demonstrated its effectiveness for increasing academic skills, peer support has not consistently been shown to be more effective than individual study. Collaboration facilitated achievement better than individual study for learning clinical psychology (Fantuzzo, Dimeff, \& Fox, 1989; Fantuzzo, Riggio, Connelly, \& Dimeff, 1989), mathematics (e.g., Reglin, 1990), statistics (e.g., Borresen, 1990; Keeler \& Steinhorst, 1994), probability (e.g., Shaughnessy, 1977), chemistry (e.g., Smith, Hinckley, \& Volk, 1991), physics (e.g., Heller, Keith, \& Anderson, 1992), and in nursing education (e.g., Frierson, 1987). On the other hand, Golbeck and Sinagra (2000) failed to demonstrate the superiority of peer collaboration over individual study for college students learning a geometric problem-solving task. Similarly, Norwood (1995) reported that, although cooperative learning was associated with superior results for postsecondary students learning precalculus, these benefits were not observed with algebra students. These results are consistent with those of Dees (1991), who found that, whereas collaboration did not benefit students' skills in solving algebraic equations, it did facilitate superior skills in solving word problems and writing proofs.

One possible explanation for the variability in study outcomes is that there are features of the collaborative learning process that contribute to its effectiveness, or lack thereof, that have not been identified empirically (Cohen, 1994; Hogan \& Tudge, 1999). For example, it is unclear what number of individuals should be involved in the collaborative learning experience to produce optimal results. Dansereau and colleagues (e.g., Dansereau, 1988) successfully demonstrated the efficacy of collaboration to facilitate text-based learning when dyads were provided with scripted interactions and prescribed peer roles. Subsequent investigations using the same procedural approach with larger groupings of students in the collaborative exchange failed to demonstrate similar achievement gains (e.g., O’Donnell et al., 1986; O'Donnell et al., 1988a, 1988b).

Similarly, the relationship among the level of structure imposed on the collaborative exchange, task complexity, and achievement outcomes is not well understood. Cohen (1994) suggested that peer interactions should be structured (e.g., using fixed roles or scripts) according to the complexity of the task to be undertaken during the exchange. Specifically, Cohen asserted that collaborative 
learning designed to promote the acquisition of lower level skills (e.g., rote memory tasks) is more effective when it is highly structured. In contrast, imposing a similar level of structure when participants are working on higher level skills (e.g., complex problem solving) is likely to interfere with, rather than benefit, achievement. It is noteworthy, however, that studies have shown benefits for the acquisition of higher order thinking skills for both structured (Heller et al., 1992; Norwood, 1995; Smith et al., 1991) and unstructured forms of collaboration (Borresen, 1990; Dees, 1991; Keeler \& Steinhorst, 1994; Reglin, 1990).

A second potential explanation for the variability observed in studies of collaborative learning in postsecondary settings may lie in the widespread lack of experimental controls. Many researchers, for example, neither randomly assigned students to treatment condition nor attempted to make statistical adjustments for the lack of random assignment (e.g., Borresen, 1990; Keeler \& Steinhorst, 1994; Reglin, 1990; Smith et al., 1991). Others failed to control adequately for the differential teaching effects, performance feedback, instructional delivery, assignments, practice length, and assessment protocols provided to their experimental versus control groups. For example, participants in Heller et al.'s (1992) study appear to have experienced differential teaching effects, as instructors in the peer-mediated condition received more training than controls.

Investigations with college students reported by Dansereau and his colleagues (e.g., O'Donnell et al., 1986; O’Donnell et al., 1988a, 1988b) and by Fantuzzo and his colleagues (e.g., Fantuzzo, Dimeff, \& Fox, 1989; Fantuzzo, Riggio, et al., 1989) are a notable exception to the lack of experimental control. These investigations incorporated strong experimental designs, and although they were of short duration, often less than $3 \mathrm{hr}$, they showed strong effects in favor of collaborative learning. In light of the short instructional time and rapid pace of the college classroom, these investigations are particularly noteworthy for their relevance for college instruction.

Although the psychology and education communities have advocated for a greater emphasis on promoting problem-solving skills (e.g., American Psychological Association, 2003), few models have been proposed for guiding problemsolving instruction. Jonassen (1997) developed an instructional model based on his classification of problems along a continuum from well structured to ill structured. In Jonassen's system, well-structured problems state all their elements and parameters, require the use of a limited number of rules, and have correct answers and a prescribed solution process. In contrast, ill-structured problems do not explicitly state all their elements, have vaguely defined goals, have multiple solution paths and multiple criteria for evaluating solutions, and are ambiguous as to which concepts, rules, or principles are needed for solving them.

Jonassen (1997) asserted that the features of effective problem-solving instruction vary according to whether problems are well or ill structured. Effective instruction in solving well-structured problems should follow six guide- 
lines: (a) teach the prerequisite concepts; (b) show visual representations of the essential parts of problems and their interrelationships; (c) model problem solving using a nonexpert who works at least two examples using strategies such as diagramming and breaking down the problem into parts, who thinks aloud, and who articulates a problem-solving procedure; (d) present practice problems; (e) support the learner's attempts to solve the practice problems by, for example, providing solutions to analogous problems; and (f) after problems are solved, reflect on their characteristics, such as what was known, what was unknown, and which solution processes were most effective. Jonassen also recommended instructing students in a problem-solving process that includes defining and representing problems, brainstorming and investigating potential strategies for solving them, and looking back and evaluating their outcomes (Jonassen; Polya, 1957).

In the present study, we incorporated Jonassen's (1997) guidelines and instructed college students in a relatively well-structured complex problem-solving task. We compared peer collaboration with individual practice for enhancing students' skills in solving mathematics problems involving Venn diagrams. Based on prior research findings in favor of collaborative practice, we predicted that college students who practiced collaboratively would outscore those who practiced individually. The particular curricular area selected for this investigation is part of the required curriculum for undergraduate education majors at many colleges and universities, including the midwestern state universities used in this study. We selected Venn diagram problems because they are complex (i.e., have many solution paths), yet they also are relatively well structured according to Jonassen's classification system. These problems also have definite right or wrong answers, which facilitated the unambiguous scoring of responses. Instructors at the state universities included in this study reported that elementary set theory, including Venn diagrams, typically is taught in three 50-min class sessions.

By using tight experimental controls, instructionally relevant material, instructional time comparable to the college classroom, and dyads of college students, this investigation extended previous studies (e.g., Dansereau, 1988; Fantuzzo, Dimeff, \& Fox, 1989). In accordance with Cohen's (1994) recommendations for teaching complex skills, this investigation allowed peers to interact without externally imposed structure.

\section{PILOT STUDIES}

Three pilot studies were conducted. Pilot Study 1 determined the extent to which students were able to solve Venn diagram problems without instruction. Pilot Study 2 assessed how well students enrolled in courses that taught elementary set theory could solve Venn diagram problems after they received classroom 
instruction from their course instructors. Pilot Study 3 investigated how well students enrolled in courses that taught elementary set theory could solve Venn diagram problems after they viewed the experimental videotapes that were developed for this investigation and practiced in groups. The pilot studies were conducted for three reasons: (a) to ascertain the difficulty level of the Venn diagram questions that had been selected to avoid ceiling and floor effects in the experimental investigation, (b) to explore the effectiveness of typical classroom instruction for teaching problem-solving skills in elementary set theory, and (c) to estimate informally the effectiveness of the experimental tapes and collaborative practice for teaching these skills.

\section{Method}

\section{Participants}

A total of 173 students participated in the pilot studies. Participants were drawn from three postsecondary settings: a small, private liberal arts college that served primarily nontraditional students (individuals holding full-time employment) and two large land-grant state universities. All three institutions were located in small- to medium-sized cities in the Midwest.

All of the liberal arts college pilot participants were enrolled in psychology research methods courses in the summer or fall semester of 1999. Their participation in the pilot study was required by their course instructor as part of the course content. For these students, pilot study participation was integrated into their course instruction as an experiential example of research participation, and it was followed by discussion regarding the function of pilot studies in the context of psychological research. All of the state university pilot participants were undergraduates drawn from lower division mathematics courses required of education majors. For these students, pilot participation was required as part of their instruction in set theory and Venn diagrams.

The 58 participants in the first pilot study included 14 liberal arts college students and 44 state university students. The 40 participants in the second pilot study included 19 students at one state university and 21 students from the other state university. All 75 participants in the third pilot study were drawn from a single state university. Participants from all three institutions were predominantly White and female.

\section{Measures and Materials}

Pilot test. Twenty problems in introductory set theory were compiled into a paper-and-pencil test. These items had appeared previously on final examinations administered in an undergraduate mathematics course required of education 
majors at one of the participating state universities. All of the problems required the application of the set operations of union, intersection, negation, or subtraction to solve abstract problems using Venn diagrams. Typical problems, as illustrated in the Appendix, required the respondent to translate a Venn diagram into set notation or vice versa.

Videotapes. Three instructional videotapes were created to ensure that all participants in each treatment condition received identical instruction. These videos included a mathematics lecture tape, a heuristic instruction tape, and a collaborative problem-solving modeling tape. The mathematics lecture and heuristic instruction tapes depicted the first author as the instructor, using a 27- $\times 34$-in easel-backed flip chart as a visual aid. This individual was a White female graduate student in school psychology with 15 years' experience as a college-level mathematics instructor. The collaborative problem-solving tape depicted two nonexpert actors at a whiteboard in a classroom setting. Both actors were White; one was a female graduate student in her $30 \mathrm{~s}$, and the other was a male professor in his 50s. The total duration of the three instructional videotapes was approximately $75 \mathrm{~min}$.

The mathematics lecture videotape (49 min) depicted an instructional lecture on elementary set theory. The instructor first introduced the concepts of definitions of set, null set, universal set, and the operations of union, intersection, complement, and set difference. She then demonstrated 11 problems that presented sets both graphically (using Venn diagrams) and as symbolic expressions (using set notation). These problems required the representation of sets described using set notation in Venn diagram form and vice versa.

The heuristic instruction videotape (6 min) introduced Polya's (1957) five classic problem-solving elements. These steps included (a) identifying the problem, (b) generating possible approaches, (c) selecting and attempting one approach, (d) trying to justify the answer, and (e) looking back over the work, checking the answer, and coming to a final conclusion.

The collaborative modeling videotape $(18 \mathrm{~min})$ depicted two actors solving Venn diagram problems as partners. One of the problems required translating a Venn diagram into set notation and the other required this transformation in the reverse direction. The examples that were modeled were very similar to the problems that are shown in the Appendix.

On the videotape, the actors made mistakes, drew diagrams, and made validating (e.g., "That will give us a good check") and corrective (e.g., "Maybe I should study this a little more before attempting another drawing") statements while working. The actors overtly modeled all of Polya's (1957) five problemsolving steps, making references to the problem-solving elements. The "instructor" (first author) joined the actors at the end of the modeling tape and confirmed the correctness of their solutions. 


\section{Procedure}

In Pilot Study 1, liberal arts college and state university students were allowed 20 min to complete the pilot test individually, without having received any college instruction in set theory. In Pilot Study 2, state university students were allowed 20 min to take the pilot test individually in the week following instruction in set theory by their course instructors. In Pilot Study 3, state university students viewed the mathematics instruction, heuristic instruction, and collaborative modeling videotapes. They subsequently worked together for $20 \mathrm{~min}$ in groups of two to four peers to solve the problems on the pilot test. The pilot participants selected their own peers for practice.

\section{Results}

For each pilot study, the participants' tests were scored and plotted. Descriptive statistics were calculated.

The 58 participants in Pilot Study 1 (noninstruction) solved correctly a mean of 2.1 out of 20 problems on the pilot test $(M d n=1, S D=2.28)$, representing a mean score of $10.5 \%$ correct. The 40 participants in Pilot Study 2 (classroom instruction) solved correctly a mean of 8.0 problems on the pilot test ( $M d n=8, S D$ $=3.79)$, representing a mean score of $40 \%$ correct. The 75 participants in Pilot Study 3 (videotaped instruction) solved correctly a mean of 7.0 problems $(M d n$ $=6, S D=4.31$ ), representing a mean score of $35 \%$ correct.

\section{Discussion}

The results of Pilot Study 1 confirmed that, prior to receiving instruction, participants did not already know how to solve problems of this type, suggesting that students at these institutions have the potential to gain from instruction in this domain. The results of Pilot Study 2 showed that even after three 50-min sessions of typical instruction from their course instructors that included homework, feedback, and practice, by and large the participants failed to master these problemsolving skills. This suggests that students at these institutions would likely benefit from improvements in instruction on how to solve problems in set theory. With the results of Pilot Study 2, the scores from Pilot Study 3 suggested that viewing the instructional, heuristic, and modeling videotapes that were developed for the present investigation and engaging in $20 \mathrm{~min}$ of unstructured collaborative practice can be almost as effective for teaching students how to solve elementary set theory problems as a full week of college instruction with homework and feedback. Based on students' overall low performance, however, we concluded that the pilot test was too difficult and replaced six of the problems on the pilot test with easier items. 


\section{MAIN STUDY}

The main investigation compared the effectiveness of unstructured collaborative practice with that of individual practice on college students' achievement in elementary set theory. The materials were developed and refined in the pilot studies.

\section{Method}

\section{Participants}

In the fall of 1999, 257 students enrolled at the same three postsecondary institutions as in the pilot studies agreed to participate in this investigation. Of these, 195 participants attended state universities and 62 were enrolled in the liberal arts college. Due to a clerical error, demographic information was not collected for 29 of the liberal arts college students. Table 1 shows the gender, age, and ethnicity of the remaining students. As can be seen from this table, the majority of participants were male and European American. The participants ranged in age from 19 to 50 years, with a mean age of 22 years.

Participants from the state universities volunteered to participate in this investigation in partial fulfillment of a research participation requirement for undergraduate courses in educational psychology and psychology. Participants from the liberal arts college were enrolled in research methods courses in psychology. They voluntarily participated in this study during one of their weekly class periods, and their participation was not tied to any course outcomes. Following the experimental session, the experimenter (first author) led a class discussion addressing the study's research design and its relation to other research methodologies.

\section{Measures and Materials}

Individual modeling videotape. A 16-min individual modeling videotape was created that paralleled the collaborative modeling videotape. This tape depicted the same actors as appeared in the collaborative modeling tape, solving identical problems in the same classroom setting. The individual version of the modeling videotape differed from the collaborative modeling tape in that each actor solved one problem, working alone and thinking aloud.

Both versions of the modeling tape followed virtually identical scripts. The solution strategies that the actors used to solve a given problem were the same for both the individual and collaborative versions of the videotape. For example, on both videotapes, the actors made the same mistakes, drew the same diagrams, and made the same number of validating and corrective statements while working. The actors overtly modeled all of Polya's (1957) five problem-solving steps, making equal numbers of references to the same problem-solving elements as 


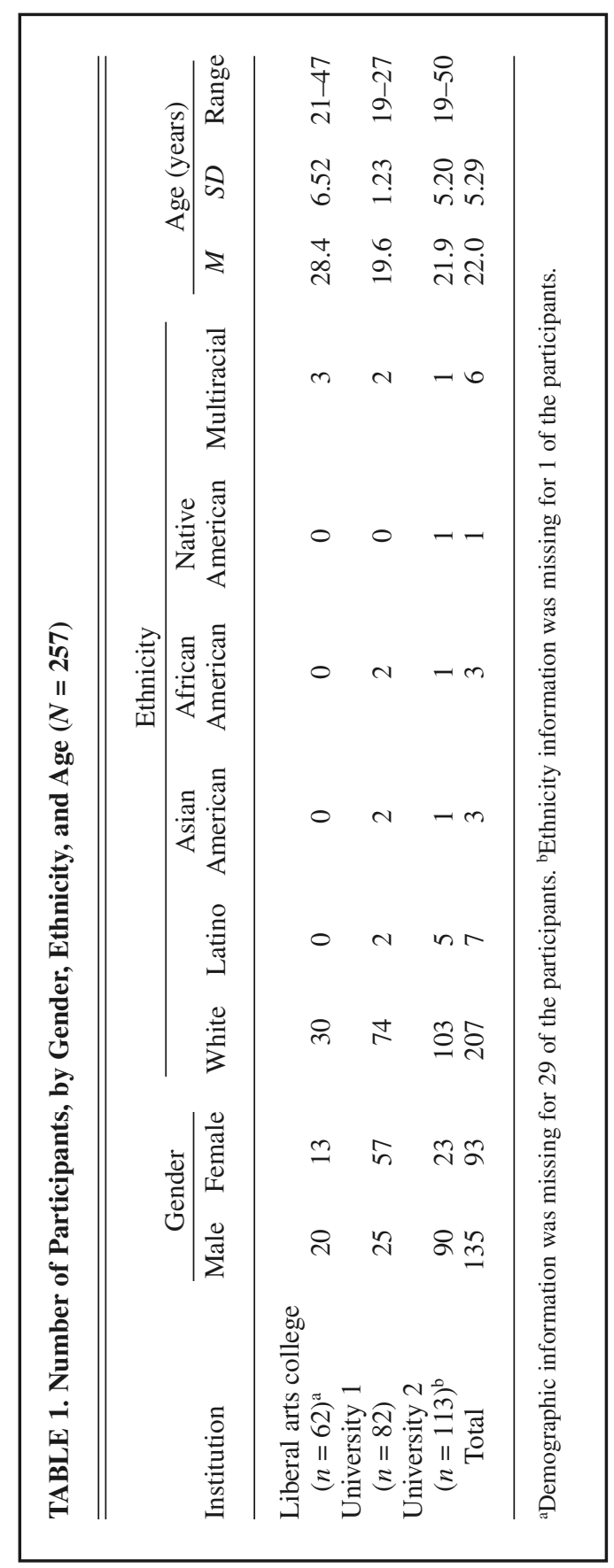


they made on the collaborative modeling tape. As on the collaborative modeling video, the first author joined the actors at the end of the tape and confirmed the correctness of their solutions.

Practice problems. The first author, a former college-level mathematics instructor, designed 10 practice problems similar to those used in the pilot test. Five of the questions required that the respondents represent sets written in set notation as Venn diagrams, and the remaining 5 questions required that the respondents reverse this transformation. See the Appendix for similar examples.

Posttest. The 20-problem posttest was a modified version of the pilot test. After analyzing the pilot participants' scores on the second and third pilot tests, we decided to replace the 6 most difficult pilot test problems with easier problems. These problems were drawn from the mathematics textbook required by one of the state universities in this study in its undergraduate course for education majors (Billstein, Libeskind, \& Lott, 1997). The remaining 14 pilot test problems were taken from the pilot test. The posttest is reproduced in the Appendix.

\section{Procedure}

The experimental investigation was conducted in a single 3-hr session. This time was roughly equivalent to the amount of time reported by mathematics faculty at both state universities for teaching introductory set theory and Venn diagrams. At those universities, this course material is most commonly taught in three 50-min class periods, $1 \mathrm{hr}$ of which is devoted to Venn diagrams.

Participants were randomly assigned to either a collaborative or individual condition, with participants in each experimental condition working in a separate room. The collaborative practice participants were paired randomly with partners.

Instruction. During approximately the first 75 min of each session, all participants viewed the mathematics lecture, heuristic instruction, and either the collaborative or the individual problem-solving modeling videotape. The mathematics lecture and heuristic instruction tapes were identical for both experimental conditions. However, the version of the problem-solving modeling tape that was viewed differed according to experimental condition. Participants who were assigned to the collaborative practice condition viewed the collaborative problem-solving modeling videotape; those assigned to the individual condition viewed the individual problem-solving modeling tape. All participants were encouraged to take notes, and they were alerted to attend to the actors' use of the problem-solving steps in the modeling videotape. After they viewed the heuristic instruction video and before they watched the modeling tape, all participants were allowed a 15-min break.

Active practice. During the next 40 min of each session, we instructed partici- 
pants in both experimental conditions to practice the skills that were introduced in the videotapes. Participants in the individual practice condition worked the 10 practice problems alone, whereas those in the collaborative practice condition worked on the practice problems with their partners. Although the participants were permitted to refer to the notes that they took during the instructional portion of the session, they received no feedback from the experimenter regarding the accuracy of their work. The practice problems were collected at the conclusion of the period.

During each practice period, the experimenter recorded the frequency of ontask behavior for each participant (individual condition) or pair (collaborative condition) using a 20 -sec momentary time-sampling procedure. On-task behavior was defined as looking at experiment-related papers, writing, or, for members of the collaborative practice condition, talking with one's partner about the material relevant to the study.

Posttest assessment. During the last $20 \mathrm{~min}$ of the session, all participants individually completed the 20 -item posttest and a brief demographic sheet. During this time, participants were not permitted to refer to their notes.

\section{Analysis}

We totaled the posttest scores for the participants at each institution. Based on these scores, we compared the individual practice and collaborative practice posttest scores obtained by the liberal arts college students with those obtained by the state university students in a $2 \times 2$ (Treatment Condition $\times$ Educational Setting) analysis of variance (ANOVA). In addition, we compared the rates of on-task behavior for the two experimental conditions.

\section{Results}

Table 2 shows the posttest scores for participants in the individual practice and collaborative practice conditions at each institution. For the students at the state universities, the posttest scores obtained by the individual practice groups $(M=$ 11.56 and $M=11.16$, respectively, out of 20) were approximately equal, and the scores by the collaborative practice groups $(M=11.98$ and $M=10.57$, respectively) also were very similar. Because these participants were drawn from very similar educational settings (state universities in the Midwest), we pooled their posttest scores for further analyses.

On the other hand, the posttest scores obtained by the liberal arts college students showed a more noticeable trend. Whereas their scores for the individualpractice participants $(M=11.22, S D=5.61)$ were comparable to those for the state university students, the scores for the collaborative group $(M=8.40, S D=$ 
TABLE 2. Posttest Scores, by Institution and Treatment Condition

\begin{tabular}{|c|c|c|c|c|c|c|c|c|c|}
\hline \multirow[b]{3}{*}{ Institution } & \multicolumn{6}{|c|}{ Treatment condition } & & & \\
\hline & \multicolumn{3}{|c|}{ Individual } & \multicolumn{3}{|c|}{ Collaborative } & \multicolumn{3}{|c|}{ Total } \\
\hline & $M$ & $S D$ & $n$ & $M$ & $S D$ & $n$ & $M$ & $S D$ & $n$ \\
\hline Liberal arts college & 11.22 & 5.61 & 32 & 8.40 & 4.17 & 30 & 9.85 & 5.13 & 62 \\
\hline University 1 & 11.16 & 4.64 & 38 & 10.57 & 4.88 & 44 & 10.84 & 4.75 & 82 \\
\hline University 2 & 11.56 & 4.93 & 59 & 11.98 & 4.68 & 54 & 11.76 & 4.79 & 113 \\
\hline Total & 11.36 & 4.99 & 129 & 10.66 & 4.81 & 128 & 11.01 & 4.90 & 257 \\
\hline
\end{tabular}

4.17) were considerably lower. Because the college served primarily nontraditional students, we conjectured that these participants were drawn from a population that was different from the other participants. Consequently, further analyses compared the participants according to their educational setting (liberal arts college vs. state university).

A $2 \times 2$ (Treatment Condition $\times$ Educational Setting) ANOVA was pursued, with individual versus collaborative practice and state university versus liberal arts college as independent variables. Results of the ANOVA revealed significant main effects for both treatment condition, $F(1,253)=4.1, p<.05$, and setting, $F(1,253)=4.9, p<.05$. On the whole, the participants who practiced individually outperformed those who practiced collaboratively, and students from the state universities outscored those from the liberal arts college. The Setting $\times$ Treatment interaction was not statistically significant, $F(1,253)=3.8, p>.05$. The effect size for treatment condition was small $(d=-0.14$; Cohen, 1988; Rosnow \& Rosenthal, 1996).

The mean frequencies of on-task behavior during practice were $99.2 \%$ and $99.3 \%$, respectively, for the individual and collaborative conditions. Mean frequencies of on-task behavior during practice were $99.2 \%$ and $99.5 \%$, respectively, for state university and liberal arts college students.

\section{Discussion}

We tested the prediction that unstructured collaborative practice would result in the development of better problem-solving skills than individual practice for college students learning elementary set theory. This hypothesis was not upheld. In fact, results showed that for this problem-solving activity, unstructured collaboration with a partner was less effective than working alone. These results are contrary to the vast majority of previously published collaborative learning studies with undergraduates, which have overwhelmingly reported peer collaboration 
to be at least as effective as individual practice for enhancing complex problemsolving skills (e.g., Dees, 1991; Springer, Stanne, \& Donovan, 1999).

A strength of this investigation is its high ecological validity. We used a curriculum that was instructionally relevant for undergraduate education majors at the state universities from which these participants were drawn and included test questions that were drawn from actual final examinations used in classes at one of the universities included in the study. The 3-hr time frame also was realistic for the college classroom, in that it closely conformed to the duration of instruction that is typically used to teach elementary set theory and Venn diagrams in mathematics classrooms at the participating state universities.

The ability to solve well-structured, complex problems is important for college students, especially in such fields as science, mathematics, engineering, and economics. Because the Venn diagram problems that we taught were relatively wellstructured and complex, the collaborative interactions were allowed to proceed without externally imposed structures, such as scripts or assigned peer roles, according to Cohen's (1994) recommendations. In addition, several instructional features, such as using nonexpert models, providing practice problems, and articulating a problem-solving procedure, were employed per Jonassen's (1997) recommendations.

The discrepancy between the present findings and prior reports of the superior, or at least equal, effectiveness of peer collaboration may be explained by the rigorous experimental controls that were included in this study. By using an experimental design, including elements such as random assignment of participants to treatment condition, presentation of equivalent materials, and use of identical procedures across treatment conditions, we controlled more rigorously for confounding factors than did many previous studies. As Dansereau (1988) noted, previous studies may have been biased in favor of collaboration due to their widespread lack of experimental controls.

A second potential reason for the failure to find an advantage in favor of peer collaboration is the short duration of this study. The experimental treatment was presented in only $3 \mathrm{hr}$. However, Dansereau and colleagues (e.g., Dansereau, 1988) demonstrated that even in studies as short as $3 \mathrm{hr}$, peer collaboration with dyads with instructionally relevant material can be shown superior to individual study for promoting achievement. In addition, although insufficient time for collaboration might result in a lack of significant effects in favor of collaboration, it is not clear how it could lead to the present findings in favor of individual practice.

A third explanation for the apparent advantage of individual practice in this experiment is that, despite the simplification of the pilot test problems, the resulting posttest still may have been too difficult for the participating students. The mean posttest scores (overall mean score of 11.01 out of 20 , which is $55 \%$ correct) confirmed that the test items were generally quite difficult for the partici- 
pants. Because the posttest problems were so difficult, instructional factors such as the short duration of the session and the briefness of the time interval between instruction and practice may have hindered performance. Although the difficulty of the posttest problems was quite representative of real-life instruction at the state universities included in this study, it may have been a poorer reflection of the liberal arts students' coursework, which may have been less likely to require mastery of these skills.

Given the evidence of the advantages of incorporating elements of positive interdependence into collaborative tasks (e.g., Johnson \& Johnson, 1990), it is possible that our failure to find an advantage in favor of collaboration is attributable to the limited nature of positive interdependence that was programmed into this task. Although our collaborative condition promoted goal interdependence by requiring partners to practice together using a single, shared worksheet, the task did not include reward interdependence (in fact, no rewards were offered). Had a reinforcement structure been included so that the students' grades reflected both their collaborative efforts and their individual posttest performance, the findings might have been different. However, although our failure to provide group rewards may help explain the lack of superiority of students in the collaborative condition, it does not explain their lower achievement compared with students who practiced alone.

Given the extant research on the relationship between student ability and the effectiveness of peer collaboration (e.g., Webb, 1992), the difficulty of this task may have been more detrimental to the performance of students who worked collaboratively than it was for those who practiced alone. In this investigation, it seems likely that random pairing led to a sizeable proportion of dyads consisting of two low-ability partners. Students' attempts to provide and receive help from their partners, therefore, may have resulted in feelings of frustration and in a lessening of effort expended, relative to those who practiced alone. Had this problem-solving task been made less difficult by, for example, allowing additional time for students to process the newly presented information prior to practicing, the students in the collaborative condition might have given more helpful explanations to their partners. Subsequently, the collaborative condition might have shown a more favorable outcome. Future researchers would do well to test the hypothesis that for difficult tasks, peer interaction may inhibit, rather than promote, achievement. It also would be interesting to examine the effects on task difficulty of allowing students more time for processing information by manipulating the amount of time provided between instruction and practice. As Cohen (1994) noted, we still do not yet completely understand precisely which collaborative learning factors are most useful for enhancing specific outcomes.

One limitation of this study relates to the analog elements of treatment. Although the situation was fairly realistic in that students received instruction and practice in college classrooms and using a college-level curriculum, participants' 
motivation to perform may have been diminished by the fact that their posttest scores had no impact on their course grades. The lack of naturalistic reinforcement for academic achievement, therefore, may have suppressed the overall performance on the task for the students in both experimental conditions. However, as mentioned earlier, it still would not easily explain the differential performance by treatment condition that was reported. Future researchers might address this limitation by studying peer-mediated tasks in the context of actual college classrooms.

A second limitation is that the present samples were drawn from a predominantly White and culturally homogeneous midwestern setting. The impact on academic achievement of interactions among peers from different racial or ethnic groups and in settings with more cultural diversity may be quite different. More research is needed in this area at the college level.

Further research that examines the types of interactions that occur between partners with tasks of this type will have the potential to further elucidate these findings. Such finer grained analyses of social interactions would be consistent with Cohen's (1994) and Barron's (2003) recommendations.

Although collaborative teaching interventions most often have been reported to be at least equal in effectiveness to individual approaches, this investigation indicates that the opposite sometimes is true. These results suggest that it is inadvisable to assume that collaborative practice will be as effective as individual practice for promoting complex problem-solving skills. Rather, it is likely that the effectiveness of peer collaboration is subject to the influence of multiple incompletely understood factors. It is incumbent on college instructors to exercise care in designing collaborative instruction for developing skill in solving complex, well-structured problems.

\section{REFERENCES}

American Psychological Association Online, President's Office. (2003). Education that works for all children. Retrieved December 27, 2003, from http://www.apa.org/about/president/initiavies.html

Barron, B. (2003). When smart groups fail. Journal of Learning Sciences, 12, 307-359.

Bender, W. N. (2002). Differentiating instruction for students with learning disabilities: Best teaching practices for general and special educators. Thousand Oaks, CA: Corwin Press.

Billstein, R., Libeskind, S., \& Lott, J. W. (1997). A problem solving approach to mathematics for elementary school teachers (6th ed.). Reading, MA: Addison-Wesley.

Borresen, C. R. (1990). Success in introductory statistics with small groups. College Teaching, 38, 26-28.

Brinckerhoff, L. C. (1996). Making the transition to higher education: Opportunities for student empowerment. Journal of Learning Disabilities, 29, 118-136.

Calhoon, M. B., \& Fuchs, L. S. (2003). The effects of peer-assisted learning strategies and curriculum-based measurement on the mathematics performance of secondary students with disabilities. Remedial and Special Education, 24, 235-245.

Cohen, E. G. (1994). Restructuring the classroom: Conditions for productive small groups. In E. Dubinsky, D. Mathews, \& B. E. Reynolds (Eds.), Readings in cooperative learning for undergraduate mathematics (pp. 135-156). Washington, DC: Mathematics Association of America. 
Cohen, J. (1988). Statistical power analysis for the behavioral sciences (2nd ed.). Hillsdale, NJ: Erlbaum.

Dansereau, D. F. (1988). Cooperative learning strategies. In C. E. Weinstein, E. T. Goetz, \& P. A. Alexander (Eds.), Learning and study strategies: Issues in assessment, instruction, and evaluation (pp. 103-120). San Diego, CA: Academic Press.

Dees, R. L. (1991). The role of cooperative learning in increasing problem-solving ability in a college remedial course. Journal for Research in Mathematics Education, 22, 409-421.

Fantuzzo, J. W., Dimeff, L. A., \& Fox, S. L. (1989). Reciprocal peer tutoring: A multimodal assessment of effectiveness with college students. Teaching of Psychology, 16, 133-135.

Fantuzzo, J. W., Riggio, R. E., Connelly, S., \& Dimeff, L. A. (1989). Effects of reciprocal peer tutoring on academic achievement and psychological adjustment: A component analysis. Journal of Educational Psychology, 81, 173-177.

Frierson, H. T., Jr. (1987). Academic performance in predominantly black nursing classes: Effects associated with intervention designed for standardized test preparation. Journal of Research and Development in Education, 20, 37-40.

Fuchs, D., Fuchs, L. S., \& Burish, P. (2000). Peer-assisted learning strategies: An evidence-based practice to promote reading achievement. Learning Disabilities Research and Practice, 15, 85-91.

Fuchs, L. S., Fuchs, D., \& Karns, K. (2001). Enhancing kindergartners' mathematical development: Effects of peer-assisted learning strategies. Elementary School Journal, 101, 495-510.

Gardner, R. III, Cartledge, G., Seidl, B., Woolsey, M. L., Schley, G. S., \& Utley, C. A. (2001). Mount Olivet after-school program: Peer-mediated interventions for at-risk students. Remedial and Special Education, 22, 22-33.

Golbeck, S. L., \& Sinagra, K. (2000). Effects of gender and collaboration on college students' performance on a Piagetian spatial task. The Journal of Experimental Education, 69, 22-35.

Heller, P., Keith, R., \& Anderson, S. (1992). Teaching problem solving through cooperative grouping: Part 1. Group versus individual problem solving. American Journal of Physics, 60, 627-636.

Hogan, D., \& Tudge, J. R. H. (1999). Implications of Vygotsky's theory for peer learning. In A. M. O’Donnell \& A. King (Eds.), Cognitive perspectives on peer learning (pp. 39-65). Mahwah, NJ: Erlbaum.

Johnson, D. W., \& Johnson, R. T. (1990). Cooperative learning and achievement. In S. Sharan (Ed.), Cooperative learning: Theory and research (pp. 23-37). New York: Praeger.

Jonassen, D. H. (1997). Instructional design models for well-structured and ill-structured problemsolving learning outcomes. Education Theory Research and Development, 45, 65-94.

Keeler, C. M., \& Steinhorst, R. K. (1994). Cooperative learning in statistics. Teaching Statistics, 16, $81-84$.

Mastropieri, M. A., Scruggs, T. E., Spencer, V., \& Fontana, J. (2003). Promoting success in high school world history: Peer tutoring versus guided notes. Learning Disabilities Research and Practice, 18, 52-65.

McDonnell, J. M., Mathot-Buckner, C., Thorson, N., \& Fister, S. (2001). Supporting the inclusion of students with moderate and severe disabilities in junior high school general education classes: The effects of classwide peer tutoring, multi-element curriculum, and accommodations. Education and Treatment of Children, 24, 141-160.

Lew, M., Mesch, D., Johnson, D. W., \& Johnson, R. (1986). Positive interdependence, academic and collaborative-skills group contingencies, and isolated students. American Educational Research Journal, 23, 476-488.

Norwood, K. S. (1995). The effects of the use of problem solving and cooperative learning on the mathematics achievement of underprepared college freshmen. Primus, 5, 229-252.

O'Donnell, A. M., Dansereau, D. F., Hythecker, V. I., Larson, C. O., Rocklin, T. R., Lambiotte, J. G., et al. (1986). The effects of monitoring on cooperative learning. The Journal of Experimental Education, 54, 169-173.

O’Donnell, A. M., Dansereau, D. F., Rocklin, T., Hythecker, V. I., Young, M. D., Hall, R. H., et al. (1988a). Cooperative procedural learning: Effects of prompting and pre- versus distributed planning activities. Journal of Educational Psychology, 80, 167-171.

O’Donnell, A. M., Dansereau, D. F., Rocklin, T., Hythecker, V. I., Young, M. D., Hall, R. H., et al. (1988b). Promoting functional literacy through cooperative learning. Journal of Reading Behavior, 20,339-356. 
Polya, M. (1957). How to solve it (2nd ed.) New York: Doubleday.

Reglin, G. L. (1990). The effects of individualized and cooperative computer assisted instruction on mathematics achievement and mathematics anxiety for prospective teachers. Journal of Research on Computing in Education, 23, 404-412.

Rosnow, R. L., \& Rosenthal, R. (1996). Computing contrasts, effect sizes, and counternulls on other people's published data: General procedures for research consumers. Psychological Methods, 1, 331-340.

Shaughnessy, M. J. (1977). Misconceptions of probability: An experiment with a small-group, activity-based, model building approach to introductory probability at the college level. Educational Studies in Mathematics, 8, 295-316.

Slavin, R. E. (1992). When and why does cooperative learning increase achievement? Theoretical and empirical perspectives. In R. Hertz-Lazarowitz \& N. Miller (Eds.), Interaction in cooperative groups: The theoretical anatomy of group learning (pp. 145-173). Cambridge, UK: Cambridge University Press.

Slavin, R. E. (1996). Research on cooperative learning and achievement: What we know, what we need to know. Contemporary Educational Psychology, 21, 43-69.

Smith, M. E., Hinckley, C. C., \& Volk, G. L. (1991). Cooperative learning in the undergraduate laboratory. Journal of Chemical Education, 68, 413-415.

Springer, L., Stanne, M. E., \& Donovan, S. S. (1999). Effects of small-group learning on undergraduates in science, mathematics, engineering, and technology: A meta-analysis. Review of Educational Research, 69, 21-51.

Vygotsky, L. S. (1978). Mind in society: The development of higher psychological processes. Cambridge, MA: Harvard University Press.

Webb, N. M. (1985). Student interaction and learning in groups: A research summary. In R. Slavin, S. Sharan, J. Kagan, R. Hertz-Lazarowitz, C. Webb, \& R. Schmuck (Eds.), Learning to cooperate, cooperating to learn (pp. 147-172). New York: Plenum.

Webb, N. M. (1992). Testing a theoretical model of student interaction and learning in small groups. In R. Hertz-Lazarowitz \& N. Miller (Eds.), Interaction in cooperative groups: The theoretical anatomy of group learning (pp. 145-173). Cambridge, UK: Cambridge University Press.

Yueh, J., \& Alessi, S. (1988). The effect of reward structure and group ability composition on cooperative computer-assisted instruction. Journal of Computer-Based Instruction, 15, 18-22.

\section{APPENDIX \\ Posttest}

Please answer the following questions in the space indicated. For each of the following problems, two Venn diagrams are given. You may use the left diagram for scratch work. Please leave your final answer on the right-hand diagram. Shade only the regions indicated in set notation.

1. Shade the region $\mathrm{B}-\mathrm{A}$ on the diagram:

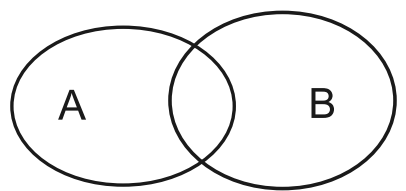

DO SCRATCHWORK HERE

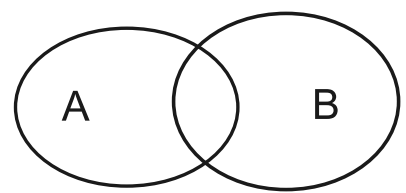

PUT FINAL ANSWER HERE

2. Shade the region $\overline{\mathrm{A}}$ on the diagram: 


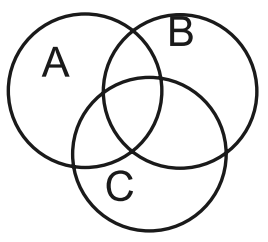

DO SCRATCHWORK HERE

3. Indicate the set $(A \cup B) \cup C$ by shading:

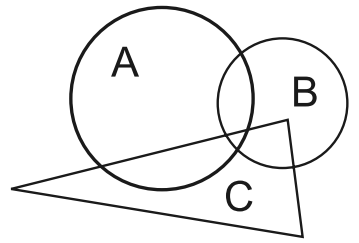

DO SCRATCHWORK HERE

4. Indicate the set $(A \cup D) \cap B$ by shading:

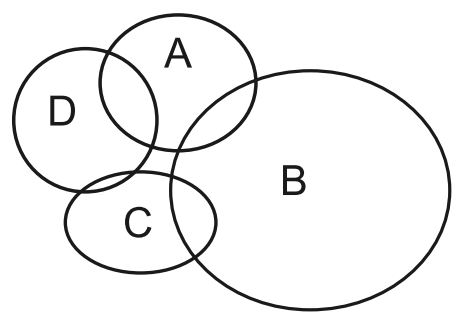

DO SCRATCHWORK HERE

5. Shade the area $(A \cap B) \cup C$ on the diagram:

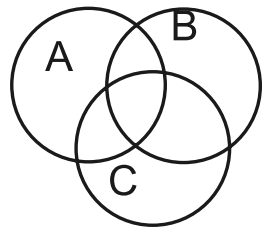

DO SCRATCHWORK HERE

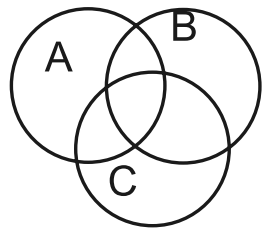

PUT FINAL ANSWER HERE

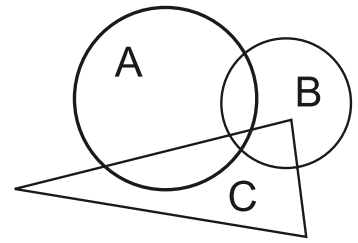

PUT FINAL ANSWER HERE

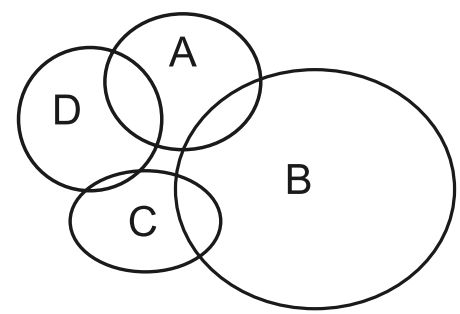

PUT FINAL ANSWER HERE

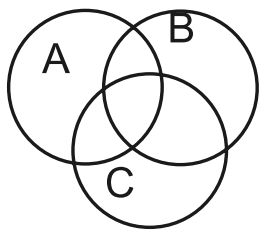

PUT FINAL ANSWER HERE

6. Shade $\overline{\mathrm{A}} \cap(\mathrm{B} \cup \mathrm{C})$ on the diagram: 


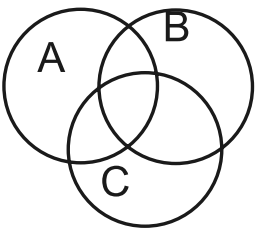

DO SCRATCHWORK HERE

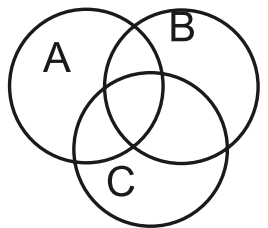

PUT FINAL ANSWER HERE

7. Shade the region corresponding with the set $\overline{(\mathrm{A} \cup \mathrm{B})} \cap \mathrm{C}$ in the Venn diagram below:

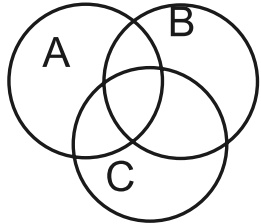

DO SCRATCHWORK HERE

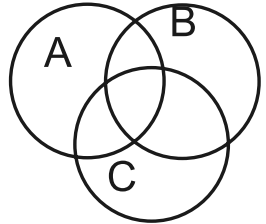

PUT FINAL ANSWER HERE

8. Indicate the set $(\mathrm{A}-\mathrm{B}) \cap \mathrm{C}$ by shading:

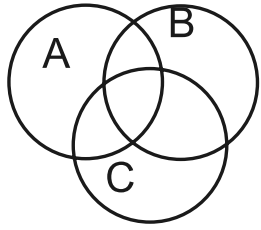

DO SCRATCHWORK HERE

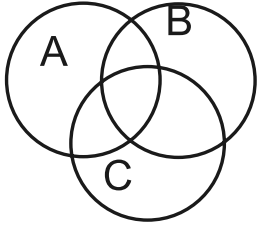

PUT FINAL ANSWER HERE

For Problems 9 and 10, suppose $\mathrm{U}$ has elements as shown:
Let $\mathrm{A}=\{\mathrm{a}, \mathrm{b}, \mathrm{c}, \mathrm{d}, \mathrm{e}\}$,
$B=\{d, e, f, g\}$,
and $\mathrm{C}=\{\mathrm{e}, \mathrm{f}, \mathrm{g}, \mathrm{h}, \mathrm{k}\}$.

a

b

C

d e

f

g

h

i

$\mathrm{k}$ 
Use Venn diagrams to find the elements contained in the following sets. List the elements of the sets:

9. $(\mathrm{A} \cap \mathrm{B})=\{\quad\}$.

10. $(B \cup C)-A=\{\quad\}$.

For Problems 11-20, please describe the shaded part of the Venn diagram using set notation (i.e., in terms of union, intersection, set negation, and/or set difference).

11. Identify the shaded region using set notation:

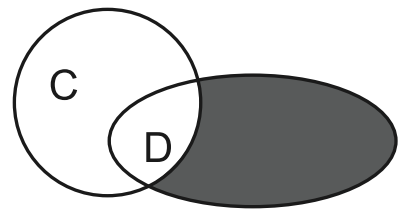

Answer:

12. Identify the shaded region using set notation:

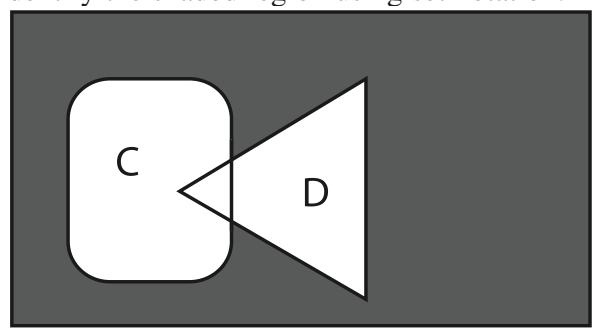

Answer:

13. Describe the shaded portion using set notation:

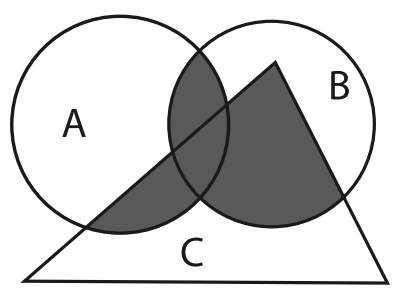

Answer:

14. Identify the shaded region using set notation: 


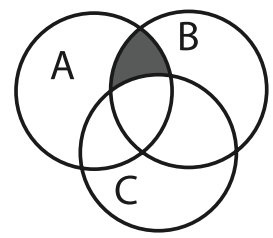

Answer:

15. Use set notation to identify the region:

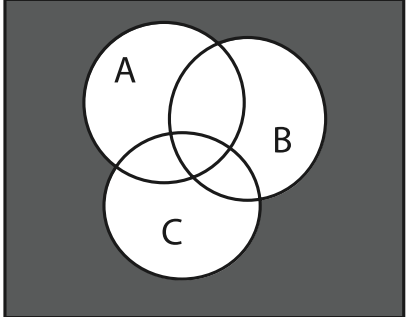

Answer:

16. Use set notation to identify the region:

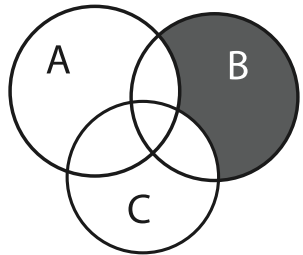

Answer:

17. Describe the shaded regions using set notation:

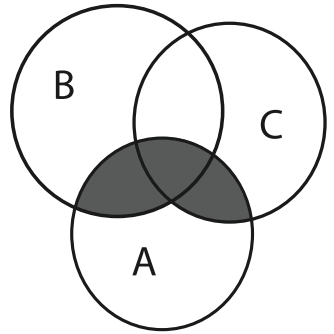

Answer:

18. Describe the shaded regions using unions, intersections, and set differences. Be sure to use parentheses where needed. 


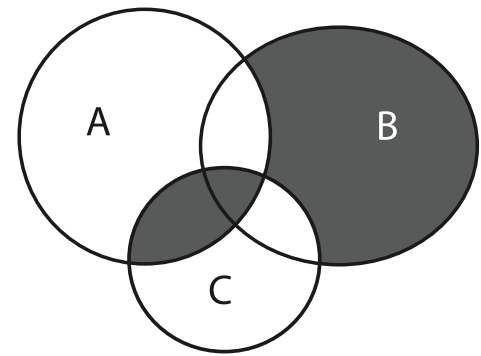

Answer:

19. Describe the shaded region using set notation:

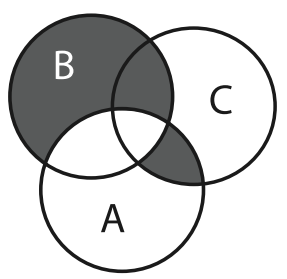

Answer:

20. Describe the shaded regions using unions, intersections, and set differences. Be sure to use parentheses where needed.

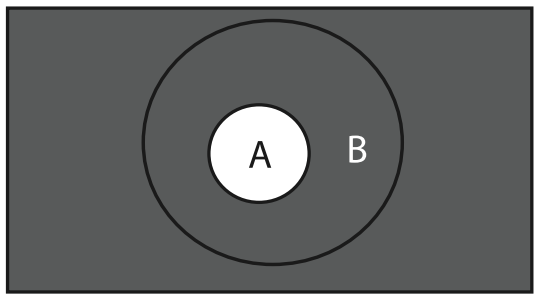

Answer: 
Copyright of Journal of Experimental Education is the property of Heldref Publications and its content may not be copied or emailed to multiple sites or posted to a listserv without the copyright holder's express written permission. However, users may print, download, or email articles for individual use. 